\title{
Bernard JACQUÉ et Georgette PASTIAUX-THIRIAT, Joseph Dufour manufacturier de papier peint
}

Rennes, Presses Universitaires de Rennes, 2010, 296 p., ISBN

978-2-7535-1236-8, 24€.

\section{Michel Biard}

\section{Q OpenEdition}

1 Journals

Édition électronique

URL : https://journals.openedition.org/ahrf/12900

DOI : 10.4000/ahrf.12900

ISSN : 1952-403X

\section{Éditeur :}

Armand Colin, Société des études robespierristes

\section{Édition imprimée}

Date de publication : 1 septembre 2013

Pagination : 219-220

ISBN : 9782200928261

ISSN : 0003-4436

\section{Référence électronique}

Michel Biard, «Bernard JACquÉ et Georgette PASTIAUX-THIRIAT, Joseph Dufour manufacturier de papier peint », Annales historiques de la Révolution française [En ligne], 373 I juillet-septembre 2013, mis en ligne le 03 octobre 2013, consulté le 01 juillet 2021. URL : http://journals.openedition.org/ahrf/12900 ; DOI : https://doi.org/10.4000/ahrf.12900

Ce document a été généré automatiquement le 1 juillet 2021.

Tous droits réservés 


\section{Bernard JACQUÉ et Georgette} PASTIAUX-THIRIAT, Joseph Dufour
manufacturier de papier peint

Rennes, Presses Universitaires de Rennes, 2010, 296 p., ISBN

978-2-7535-1236-8, 24€.

Michel Biard

\section{RÉFÉRENCE}

Bernard JACQUÉ et Georgette PASTIAUX-THIRIAT, Joseph Dufour manufacturier de papier peint. Rennes, Presses Universitaires de Rennes, 2010, 296 p., ISBN 978-2-7535-1236-8, $24 €$.

1 Publication des Actes de journées d'étude tenues en mai 2009 à Tramoyes (Saône-etLoire), lieu de naissance de Joseph Dufour, cet ouvrage permet de faire le point sur un homme quelque peu oublié, qui eut pourtant une vie intéressante à bien des égards et dont le patronyme connut surtout une célébrité rendue durable par les superbes papiers peints créés par son entreprise. Organisé en quatre parties, le livre entend tout d'abord évoquer "l'homme Dufour", avant d'aborder successivement la question des sources, la «réalité des papiers peints» et les problèmes liés à leur conservation/ restauration. Cela supposait de rassembler des historiens, des historiens de l'Art, des conservateurs, mais aussi des spécialistes de la restauration en charge de ce type d'œuvres. Le pari ne manquait pas d'une certaine audace et il convient de rendre hommage aux initiateurs du projet, car il est assurément couronné de succès avec comme résultat ce livre passionnant et très richement illustré par plusieurs dizaines de reproductions (pour l'immense majorité en couleurs).

2 Né en 1754, élève de l'École de dessin de Lyon, Joseph Dufour participe en 1785 avec trois associés à la création d'une manufacture de papiers peints. En décembre 1789, son nom apparait parmi les signataires d'une adresse de «citoyens patriotes » de Lyon. Pour autant, on ne sait rien de ses engagements militants avant 1793. Présent à Paris au 
début de l'été de cette année terrible pour la jeune République, il fait partie du petit groupe de citoyens de confiance choisis par Collot d'Herbois pour l'accompagner dans sa mission lyonnaise à l'automne. On ignore hélas les raisons de ce choix (Paul Chopelin émet l'hypothèse d'une rencontre récente entre les deux hommes, mais dans l'absolu celle-ci pourrait aussi dater des années lyonnaises de Collot d'Herbois avant la Révolution). Quoi qu'il en soit, Dufour s'intègre alors parmi les administrateurs du département du Rhône nommés par les représentants du peuple en mission après la reprise de la ville « rebelle ». Il participe donc directement à la réorganisation de la cité, désormais nommée Commune-Affranchie ou Ville-Affranchie, sans pour autant se voir confier des responsabilités personnelles au sein des tribunaux extraordinaires mis en place pour juger les «rebelles». Après Thermidor et en dépit d'une adresse approuvant, comme on s'en doute, le coup de force contre « le dictateur Robespierre et ses vils complices ", Dufour semble ne pas pouvoir échapper à l'épuration des autorités constituées. Néanmoins, en vertu d'un «jeu de chaises musicales» comme il s'en produit ailleurs, il ne quitte tout d'abord l'administration du département que pour être nommé président de celle du district, grâce au soutien du représentant du peuple Reverchon (élu, rappelons-le, en Saône-et-Loire). Répit de courte durée car une nouvelle épuration l'écarte à l'automne 1794. Pour autant, il n'est pas arrêté et parvient à quitter Lyon pour rejoindre la Saône-et-Loire au printemps 1795, toujours grâce à la protection de Reverchon. Sous le Directoire, ici étudié par Bernard Gainot, Dufour s'installe à Mâcon et s'intègre aux réseaux républicains opposés aux " réacteurs ", liés aux néo-jacobins, actifs notamment grâce à la présence de nombreux réfugiés venus de Lyon. Parmi les actionnaires de son entreprise de papiers peints, figurent Reverchon (pour la coquette somme de 28000 livres), mais aussi «Sonthonax de Paris » (pour 800 livres). En tant que manufacturier, il possède déjà un réseau de relations dans le milieu des marchands et fabricants parisiens, ce qui facilite son installation dans le faubourg Saint-Antoine à l'automne 1806. La suite de son parcours se confond pour l'essentiel avec ses productions.

3 Grâce à la présence d'un riche fonds au Musée des Arts décoratifs de Paris, Véronique de la Hougue évoque les différentes expositions dans lesquelles les papiers peints de Dufour ont été montrés au public, de celles du XIX siècle à l'exposition « Trois siècles de papiers peints » en 1967. Après cette dernière, le musée a continué d'acheter des œuvres de Dufour mais aussi des documents d'archives (ainsi les archives Dufour et Leroy acquises en 2006), tandis que les "maquettes" conservées à la Bibliothèque Forney (quelque 300 pièces) permettaient d'étudier les dessinateurs ayant travaillé pour Dufour. Leur influence et celle de leurs créations se découvrent à travers leur présence dans plusieurs pays européens. En Grande-Bretagne (étudiée par Christine Woods), plusieurs grandes collections de papiers peints historiques existent aujourd'hui, dont celle de la Whitworth Art Gallery qui détient plusieurs papiers créés chez Dufour. On y trouve notamment de très belles grisailles représentant les Douze mois, témoignage de ce "que le fabricant était hautement considéré comme un pionnier, un novateur, un inventeur ». Dans les territoires allemands (objets de la communication de Sabine Thümmler), le bon accueil réservé à ces papiers peints est certain et plusieurs photographies de pièces ainsi décorées permettent au lecteur de mieux comprendre l'ambiance qu'ils contribuaient à créer (les grisailles de Rüdlingsdorf, en Saxe, méritent à elles seules le détour). Bernard Jacqué nous donne également à voir comment le goût pour la draperie dans le style néo-classique sert lui aussi l'inspiration des dessinateurs travaillant pour Dufour, et là encore les 
photographies illustrent à quel point le trompe-l'œil est réussi (à condition pour le tapissier de réussir à résoudre nombre de problèmes de pose des papiers!). Quand ils n'illustrent pas les mois de l'année et ne donnent point ainsi l'illusion de la draperie, quand ils ne représentent pas « les monuments de Paris » ou des scènes mythologiques, quand ils ne font pas assaut de couleurs sublimes et de motifs décoratifs divers, les artistes cèdent volontiers à une autre mode, celle de "l'exotisme" (Céline Borello). Tandis que Charles Alexandre Lesueur ramène de saisissants dessins pris sur le vif lors de son expédition dans les terres australes, d'autres artistes laissent voguer leur seule imagination grâce aux récits de voyages qui leur permettent de mettre en scène « les sauvages de la Mer Pacifique » (1804) sans quitter la France. Nous nous retrouvons là en plein mythe du «bon sauvage », avec, entre autres, ces «femmes séduisantes, femmes lascives, femmes offertes »... et l'auteur d'évoquer bien entendu Marlon Brando dans Les Révoltés du Bounty, à qui j'adjoindrais volontiers Clark Gable dans la première version du film consacré aux mésaventures du capitaine Bligh en 1789. Le choix de sujets semblables, mais aussi ceux empruntés à la mythologie, autorise Georgette Pastiaux-Thiriat à pister les sources d'inspiration des dessinateurs. La liste des œuvres littéraires ne livre guère de révélations surprenantes (La Harpe, Marmontel, Bernardin de Saint-Pierre, Le Tasse, etc.). Autant d'auteurs ici fidèlement illustrés, là objets de choix liés aux «impératifs de la composition esthétique ». On lira avec un intérêt particulier les développements consacrés aux « Voyages d'Anthénor », papiers peints inspirés d'un livre de Lantier (1798) et dans lesquels peuvent être décelées des allusions à la Révolution.

4 En toute justice, il faudrait encore mentionner chacune des autres communications, avec par exemple celle qui traite des papiers peints anglais néo-classiques, celles qui abordent les matériaux et les aspects techniques, ou encore les problèmes de la conservation et ceux (liés) de la restauration... Dans le cadre limité de ce compte rendu, bornons-nous à souligner une nouvelle fois la grande richesse de cet ouvrage, même s'il aurait gagné à être agrémenté d'une chronologie synthétique, d'index, voire (pourquoi pas ?) d'une liste de lieux et de collections à découvrir sur la piste de Dufour. 